\title{
Digit Ratio and its Influence on Physical Performance: A Literature Review
}

\author{
Sérgio LC dos Santos ${ }^{* 1,3}$, Guilherme Y Furyama ${ }^{1}$, Diego LS Paza ${ }^{1}$, Gian C Pierozan ${ }^{1}$, Erika S dos Santos ${ }^{2}$ \\ ${ }^{1}$ Federal University of Paraná (UFPR), Center for Sports Talent Studies, Brazil \\ ${ }^{2}$ Pontifical Catholic University of Paraná (PUC-PR), Brazil
}

${ }^{3}$ University of Barcelona, Spain

*Corresponding author: Sérgio Luiz Carlos dos Santos, Federal University of Paraná, Center for Sports Talent Studies, Brazil

\begin{tabular}{|c|c|}
\hline ARTICLE INFO & ABSTRACT \\
\hline Received: 㓞 February 01, 2019 & Prenatal androgen exposure has much importance in organizational questions in the \\
\hline Published: 幽 February 19, 2019 & $\begin{array}{l}\text { human body. With it, the development of the human being is possible physically, behavio- } \\
\text { rally and psychologically in addition to allowing the detection of sports talents. To meas- }\end{array}$ \\
\hline $\begin{array}{l}\text { Citation: Sérgio LC dos S, Guilherme } \\
\text { Y, Diego LS P, Gian C P, Erika S dos S. } \\
\text { Digit Ratio and its Influence on Physi- } \\
\text { cal Performance: A Literature Review. } \\
\text { Biomed J Sci \& Tech Res 14(5)-2019. } \\
\text { BJSTR. MS.ID.002612. }\end{array}$ & $\begin{array}{l}\text { ure this exposure, the digit ratio (2D:4D) is the most used tool in academic papers. Using } \\
\text { the length of the index finger and ring finger, this value can be translated indirectly in } \\
\text { a simple way to understand. As the cardiovascular system is the main affected by fetal } \\
\text { testosterone, sports which involve the physical endurance generally present a very signifi- } \\
\text { cant relation with the marker digit ratio. Besides involving performance, the digit ratio can } \\
\text { present relation with individual aggressiveness. Using a good quantity of studies already } \\
\text { realized, it follows that digit ratio can really correlate its values with physical performance }\end{array}$ \\
\hline Keywords: Digit Ratio; Aerobic & \\
\hline
\end{tabular}
Exercise and Physical Performance; 2D:4D

\section{Introduction}

Physical performance is constantly improved by new training methods, physical structures more suitable and enabled for an athlete approach, or by the improvement in the detection of sports talents. In addition to understanding factors such as physical training, physiological and anthropometric properties and psychological factors, a determination of a specific physical profile according to a sporting modality may represent an important aspect in the identification and development of sports talents [1-4]. Within the patterns, frequently, certain anthropometric measurements are used, among them the digit ratio or 2D:4D. The digit ratio is an indirect marker of prenatal androgen, which contains information on the amount of exposure to testosterone and estrogen in a window of the fetal development period between the eighth and tenth week of gestation [5]. This exposure may affect several areas of the individual, such as the brain, skeleton, muscles, and circulatory system and behavioral $[6,7]$.
For the evaluation of its values, the 2D:4D uses the ratio of the annular finger and indicator, of the same hand, to analyze the individual's level of exposure to prenatal testosterone in relation to estrogen. So, the lower the value obtained from this ratio, the higher the level of exposure to prenatal testosterone. As their values do not change significantly throughout life [8] and are not related to age or physical factors (height, weight or body mass index), they can be applied to any individual [9], becoming a marker with global application. From this, several studies have analyzed the relationship between the level of androgens and the capacity of the cardiovascular system $[10,11]$. It is verified that in all the sports modalities, there is a great dependence of a developed cardiovascular system, with this, the objective of the present revision was to verify the validity of the effects of exposure to prenatal testosterone, using the marker digit ratio in the physical sport performance. 


\section{Methods}

To perform this literature review, two electronic databases were consulted: PubMed and ScienceDirect. There were no language delimitations or date of publication. The main keyword used to conduct the search was digit ratio with Boolean operator AND and the secondary words: running, endurance, speed, sprint, aerobic and agility. To limit the acquisition of too much material that would not address the theme, the fields where the descriptors appeared were limited in: title, abstract or keywords. The search resulted in 22 articles (5 on the Science Direct database and 18 on the PubMed database). Three studies were excluded because used in their sample animals and not humans, and one was excluded because the study that did not address physical performance issues. Therefore, for the formulation of this review, 18 original articles were used.

\section{Results}

\section{Pre-Natal Androgen and Their Modifications}

Great levels of fetal androgens, especially testosterone, promote the development and maintenance of various capacities, such as resistance, rhythm, velocity, better visuospatial abilities [12], muscular hypertrophy [13], increased strength [14,15], decrease in fat body mass, increase in hematocrit, reduced reaction times [16], preparedness for engaging in stressful situations and sports [17] and especially the promotion of an efficient cardiovascular system $[10,11]$.

According to Manning et al. [18], this is due to adjustments made by exposure to prenatal androgen, in characteristics that influence physical resistance and the aerobic component, such as running resistance, running economy, increased maximal oxygen uptake (VO2max) and improved vascular components $[19,20]$.

On the other hand, valences that do not involve resistance are not so well covered by prenatal testosterone exposure, such as strength or potency [21]. The digit ratio was able to explain variations of $2 \%$ in speed sprints [21] and even $10 \%$ in sports that require a combination of strength and aerobic capacity [17]. These values are still too small compared to the 25 to $30 \%$ variation in the performance of medium- and long-distance athletes [18,22]. The analysis of the digit ratio can also be related to changes observed in behavioral scope. Decreased values of 2D:4D may cause changes that influence performance, such as increased confidence [23], aggressiveness [24,25], competitiveness [26] and dominance [27].

A model proposed by Geschwind \& Galaburda [28] also suggests that prenatal testosterone tends to slow the development of certain areas of the left hemisphere of the brain, while favoring the right. As men generally have higher levels of testosterone, brain maturation eventually favors right hemisphere skills [29]. This pattern of neurological development may be advantageous for physical activities by predisposing and stimulating the athletic ability of the individuals [30].

\section{Relationship with Aggressively}

In addition to influencing organizational situations previously mentioned, the digit ratio presents concrete evidence of its mediation in the sensitivity to the testosterone itself throughout the life cycle of the individual [31]. Despite presenting a relationship with the sensitivity and stimulation of the hormone, there is no evidence for a strong association between 2D:4D and circulating testosterone levels. In the Manning et al. [32] study, a correlation was found between this level, however, subsequent reviews with larger samples concluded that the association was weak or null $[22,33]$.

Hill et al. [34] and Kilduff et al. [31] showed that left-right digit ratio values were shown to be a marker for the increase of free testosterone levels in challenging conditions (physical, aggressive or sexual), where the lowest values had higher levels of free testosterone. So, if the hormone is increased in stressful situations and 2D:4D is a predictor of sports performance, and then it can also predict this "activation" of testosterone during physical and aggressive situations [35]. It is assumed that these testosterone peaks can be reserved for relevant situations, including sports competitions $[27,36]$, aggressive and sexual confrontations $[37,38]$. Increases in free testosterone levels may occur immediately before or during physical challenges such as football matches [27], tennis [39] and judo competitions [40].

\section{Other Variables Associated with Digit Ratio}

Manning \& Taylor [17] obtained fantastic results for the solidification of the digit ratio as a predictor of physical performance. In a study with 304 professional soccer players active or retired at various levels (international, first, second and third leagues, starter, reserves and juniors) several considerations were made: (I) professional players obtained lower values of 2D:4D than control groups that reflected the population mean; (II) titular players have lower digit ratio values compared to reserves and juniors; (III) players of international level had lower value of digit ratio when compared to players who did not reach that level; (IV) in professionals of international level who have already finished their careers, lower value of difference right-left (Dr-l) was associated with larger numbers of international apparitions; (V) there was a general increase in 2D:4D values starting from international players towards the less disputed leagues.

Several researches show that athletes of different sports modalities have lower values of digit ratio when compared to the general population. In a study by Moffit \& Swanik [6], football and gymnastics athletes showed these results with high levels of significance ( $p=0.000$ and $p=0.001$, respectively). Kabbadi players (similar to rugby) also have a lower value of 2D:4D compared to the control group (population in general, non-athlete) [41]. The same situation was observed in women, where amateur athletes have lower values of 2D:4D compared to women not engaged in sports [42]. 
Manning [43] found in a sample of 71 men athletes, from English clubs, who regularly trained and competed in the $800 \mathrm{~m}$ and $1500 \mathrm{~m}$ athletics modalities, a significant positive correlation between 2D:4DR (right hand) and 2D:4DL (left hand) with the times of the last three events performed by the individuals. In cross-country winter races, 117 men were evaluated (97 individuals for $800 \mathrm{~m}$ and 67 for $1500 \mathrm{~m}$ ) in Manning et al. [44] studies. It was observed that the best times reported by the participants were significantly correlated with the values of 2D:4DR (right hand). Furthermore, in the 800-meter sample, the values were independent of the age factor and significant when compared to Dr-l.

Kociuba et al. [45] compared military and civilian career students. In the males, no difference was observed in the 2D:4D values between the two groups, but with the female sample, a clear and significant difference was observed, where the values of the right hand $(p<0.001)$ and left hand $(p<0.01)$ digit ratio was lower in the military group when compared to the civilian group. It is believed that women with higher physical abilities, higher levels of confidence and motivation may be more likely to choose challenging jobs, such as a military course. After military recruitment, selected students tend to present masculinized aspects more often, since the requirement for intense exercises becomes much greater over time [45]. In a sample of half-marathon runners, significant correlations were found between the 2D:4D values and the final race time in both men and women. Even with both significant values, the male sex ratio was stronger than that of the female sex [46].

The findings of Bescós et al. [9] show that the Dr-l digit ratio was associated with better current and past ranking positions, regardless of training intensity and years of fencing experience. Differences were found in that sport modalities: men who participated in the most aggressive modality - saber - had lower values of digit ratio when compared to the other two modalities - foil and sword. In the same study, it was also identified that left-handed athletes obtained lower values of digit ratio and also had better current and past rankings in the world ranking. The ethnicity, height, weight and years of international experience were considered in the research, guaranteeing higher levels of reliability.

In a study by Hill et al. [34] boys who have lower values of Dr-l reached higher levels of maximum oxygen consumption (VO2max), maximum oxygen consumption rate (vVO2max), and maximum lactate concentration (LAmax) than boys who have higher values of 2D:4D right-left. Age did not affect the results obtained. Tamiya et al. [47] found a negative correlation between the digit ratio value and percentage of victories and ranking in sumo wrestlers, suggesting that the higher level of prenatal testosterone may have positively influenced athletic progress in the modality. Even with weight and height control of the athletes, values continued to be associated with 2D:4D, showing that body mass had no significant effect on sumo performance as the digit ratio.
Although indications that the digit ratio affects more endurance sports, Manning \& Hill [21] found satisfactory results in a sample of boys, where a positive correlation was observed between times of the sprints of 50 meters with 2D:4D values of the right hand. The performance was lower in athletes with higher values of digit ratio, and without influence of age, body mass index and maturation index, the correlation continued with significant values.

\section{Conclusion}

The present review shows the different approaches that the digit ratio can provide to the field of physical performance. Several methods analyzes and results can be achieved using 2D:4D. The studies presented above show that there is a relation between the athletic capacity of the individuals with their respective modalities, and a great part of the studies ends up reaching significant levels. When this value is not obtained, a trend is shown at least, showing the potential of 2D:4D in the scientific field. Even using a relatively low amount of articles, it can be concluded that the digit ratio or 2D:4D, is an important marker for predicting physical performance in some modalities. Longitudinal studies are needed to see if this question can be approached from sports initiation as a child, and whether these values actually confirm with the individual maturation.

\section{References}

1. Böhme MTS (2010) Treinamento a longo prazo e o processo de detecção, seleção e promoção de talentos esportivos. Revista Brasileira de Ciências do Esporte 21: 2.

2. Brum PC, Forjaz CDM, Tinucci T, Negrão CE (2004) Adaptações agudas e crônicas do exercício físico no sistema cardiovascular. Revista Paulista de Educação Física 18(1): 21-31.

3. Hebbelinck M (1989) Identificação e desenvolvimento de talentos no esporte: relatos cineantropométricos. Revista Brasileira de Ciência e Movimento 4(1): 46-62.

4. Loures DL, Sant'anna I, Baldotto CSDR, Sousa EBD, Nóbrega ACLD (2002) Estresse mental e sistema cardiovascular. Arquivos Brasileiros de Cardiologia 78(5): 525-530

5. Malas MA, Dogan S, Evcil EH, Desdicioglu K (2006) Fetal development of the hand, digits and digit ratio (2D:4D). Early Human Development 82(7): 469-475.

6. Moffit DM, Swanik CB (2011) The association between athleticism, prenatal testosterone, and finger length. Journal of Strength and Conditioning Research 25(4): 1085-1088.

7. Zheng Z, Cohn MJ (2011) Developmental basis of sexually dimorphic digit ratios. Proceedings of the National Academy of Sciences 108(39): 16289-16294.

8. McIntyre MH, Ellison PT, Lieberman DE, Demerath E, Towne B (2005) The development of sex differences in digital formula from infancy in the Fels Longitudinal study. Proceedings of the Royal Society of London B 272(1571): 1473-1479.

9. Bescós R, Esteve M, Porta J, Mateu M, Irurtia A, et al. (2009) Prenatal programming of sporting success: associations of digit ratio (2D:4D), a putative marker for prenatal androgen action, with world rankings in female fencers. Journal of Sports Sciences 27(6): 625-632.

10. Manning JT, Bundred PE (2000) The ratio of $2^{\text {nd }}$ to $4^{\text {th }}$ digit length: a new predictor of disease predisposition? Medical Hypotheses 54(5): 855857. 
11. Pokrywka L, Rachon D, Suchecka-Rachon K, Bitel L (2005) The second to fourth digit ratio in elite and non-elite female athletes. American Journal of Human Biology 17(6): 796-800.

12. Puts DA, McDaniel MA, Jordan CL, Breedlove SM (2008) Spatial ability and prenatal androgens: meta-analyses of congenital adrenal hyperplasia and digit ratio (2D:4D) studies. Archives of Sexual Behavior 37(1): 100-111.

13. Sinha-Hikim I, Taylor WE, Gonzalez-Cadavid NF, Zheng W, Bhasin S (2004) Androgen receptor in human skeletal muscle and cultured muscle satellite cells: Upregulation by androgen treatment. Journal of Clinical Endocrinology and Metabolism 89(10): 5245-5255.

14. Bhasin S, Woodhouse L, Storer TW (2011) Proof of the effect of testosterone on skeletal muscle. Journal of Endocrinology 170(1): 2738.

15. Herbst KL, Bhasin S (2004) Testosterone action on skeletal muscle. Current Opinion in Clinical Nutrition and Metabolism Care 7(3): 271277.

16. Salminen E, Portin R, Koskinen A, Helenius H, Nurmi M (2004) Associations between serum testosterone fall and cognitive function in prostate cancer patients. Clinical Cancer Research 10(22): 7575-7582.

17. Manning JT, Taylor RP (2001) $2^{\text {nd }}$ to $4^{\text {th }}$ digit ratio and male ability in sport: Implications for sexual selection in humans. Evolution and Human Behavior 22(1): 61-69.

18. Manning JT, Morris L, Caswell N (2007) Endurance running and digit ratio (2D:4D): implications for fetal testosterone effects on running speed and vascular health. American Journal of Human Biology 19(3): 416-421.

19. Daniels J, Daniels N (1992) Running economy of elite and non-elite female runners. Medicine and Science in Sports and Exercise 24(4): 483-489.

20. Helgerud J, Ingjer F, Stromme SB (1990) Sex differences in performancematched marathon runners. European Journal of Applied Physiology 61(5-6): 433-439.

21. Manning JT, Hill MR (2009) Digit ratio (2D:4D) and sprinting speed in boys. American Journal of Human Biology 21: 210-213.

22. Honekopp J, Schuster M (2010) A meta-analysis on 2D:4D and athletic prowess: Substantial relationships but neither hand out-predicts the other. Personality and Individual Differences 48(1): 4-10.

23. Boissy A, Bouissou MF (1994) Effects of androgen treatment on behavioral and physiological responses of heifers to fear-eliciting situations. Hormones and Behavior 28(1): 66-83.

24. Benderlioglu Z, Nelson RJ (2004) Digit length ratios predict reactive aggression in women, but not in men. Hormones and Behavior 46(5): 558-564.

25. Wilson GD (1983) Finger-length as an index of assertiveness in women. Personality and Individual Differences 4(1): 111-112.

26. Hampson E, Ellis CL, Tenk CM (2008) On the relation between 2D:4D and sex-dimorphic personality traits. Archives of Sexual Behavior 37(1): 133-144.

27. Neave N, Wolfson S (2003) Testosterone, territoriality and the 'home advantage'. Physiology and Behaviour 78(2): 269-275.

28. Geschwind N, Galaburda AM (1985) Cerebral lateralization. Biological mechanisms, association, and pathology: A hypothesis and a program for research. Archives of Neurology 43(5): 428-654.

29. Saladin KS (2004) Anatomy \& Physiology: The Unity of Form and Function ( $3^{\text {rd }}$ edn.), NY: McGraw-Hill, New York, USA.
30. Fink B, Thanzami V, Seydel H, Manning JT (2006) Digit ratio and handgrip strength in German and Mizos men: Cross-cultural evidence for an organizing effect of prenatal testosterone on strength. American Journal of Human Biology 18(6): 776-782.

31. Kilduff L, Cook CJ, Bennett M, Crewther B, Bracken RM, et al. (2013) Right-left digit ratio (2D:4D) predicts free testosterone levels associated with a physical challenge. Journal of Sports Sciences 31(6): 677-683.

32. Manning JT, Scutt D, Wilson J, Lewis-Jones DI (1998) The ratio of $2^{\text {nd }}$ to $4^{\text {th }}$ digit length: A predictor of sperm numbers and concentrations of testosterone, luteinizing hormone and oestrogen. Human Reproduction. 13(11): 3000-3004.

33. Manning JT, Wood S, Vang E, Walton J, Bundred PE, et al. (2004) Second to fourth digit ratio (2D:4D) and testosterone in men. Asian Journal of Andrology 6(3): 211-215.

34. Hill R, Simpson B, Manning JT, Kilduff L (2012) Right-left digit ratio (2D:4D) and $\mathrm{VO}_{2}$ max. Journal of Sports Sciences 30(2): 129-134.

35. Manning JT, Kilduff L, Cook C, Crewther B, Fink B (2014) Digit ratio (2D:4D): a biomarker for prenatal sex steroids and adult sex steroids in challenge situations. Frontiers in Endocrinology 30(5): 1-5.

36. Edwards DA, Waters J, Weiss A, Jarvis A (2007) Intercollegiate athletics: competition increases saliva testosterone in women soccer, volleyball, and softball players. In: Ardis LI. Testosterone research trends. Nova Science Publishers Inc pp. 195-209.

37. Elias M (1981) Serum cortisol, testosterone, and testosterone-binding globulin responses to competitive fighting in human males. Aggressive Behavior 7(3): 215-224.

38. Escasa MJ, Casey JF, Gray PB (2011) Salivary testosterone levels in men at a U.S. sex club. Archives of Sexual Behavior 40: 921-926.

39. Booth A, Shelley G, Mazur A, Tharp G, Kittok R (1989) Testosterone, and winning and losing in human competition. Hormones and Behavior 23(4): 556-571.

40. Salvador A, Suay F, Gonzalez-Bono E, Serrano MA (2003) Anticipatory cortisol, testosterone and psychological responses to judo competition in young men. Psychoneuroendocrinology 28(3): 364-375.

41. Sudhakar HH, Majumdar P, Umesh V, Panda K (2014) Second to fourth digit ratio is a predictor of sporting ability in elite Indian male kabaddi players. Asian Journal of Sports Medicine 5(3): 1-4.

42. Latourelle SM, Elwess NL, Elwess JM (2008) Finger forecasting: a pointer to athletic prowess in women -a preliminary investigation by an undergraduate biology class. American Biology Teacher 70: 411-414.

43. Manning JT (2002) Digit Ratio: A Pointer to Fertility, Behavior, and Health. New Brunswick, NJ: Rutgers University Press.

44. Manning JT, Bundred PE, Taylor RP (2003) The ratio of $2^{\text {nd }}$ and $4^{\text {th }}$ digit length: a prenatal correlate of ability in sport. In: Reilly T, Marfell-Jones M. Kinanthropometry VIII: Proceedings of the $8^{\text {th }}$ International Conference of the International Society for the Advancement of Kinanthropometry (ISAK). Routledge, London, pp. 165-174.

45. Kociuba M, Koziel S, Chakraborty R (2015) SEX DIFFERENCES IN DIGIT RATIO (2D:4D) AMONG MILITARY AND CIVIL COHORTS AT A MILITARY ACADEMY IN WROCŁAW, POLAND. Journal of Biosocial Science 48(5): 658-671.

46. Longman D, Wells JCK, Stock JT (2015) Can Persistence Hunting Signal Male Quality? A Test Considering Digit Ratio in Endurance Athletes. PLOS ONE 4: 1-12.

47. Tamiya R, Lee SY, Ohtake F (2012) Second to fourth digit ratio and the sporting success of sumo wrestlers. Evolution and Human Behavior 33(2): 130-136. 


\section{ISSN: 2574-1241}

DOI: 10.26717.BJSTR.2019.14.002612

Sérgio Luiz Carlos dos Santos. Biomed J Sci \& Tech Res

(c) This work is licensed under Creative

Submission Link: https://biomedres.us/submit-manuscript.php

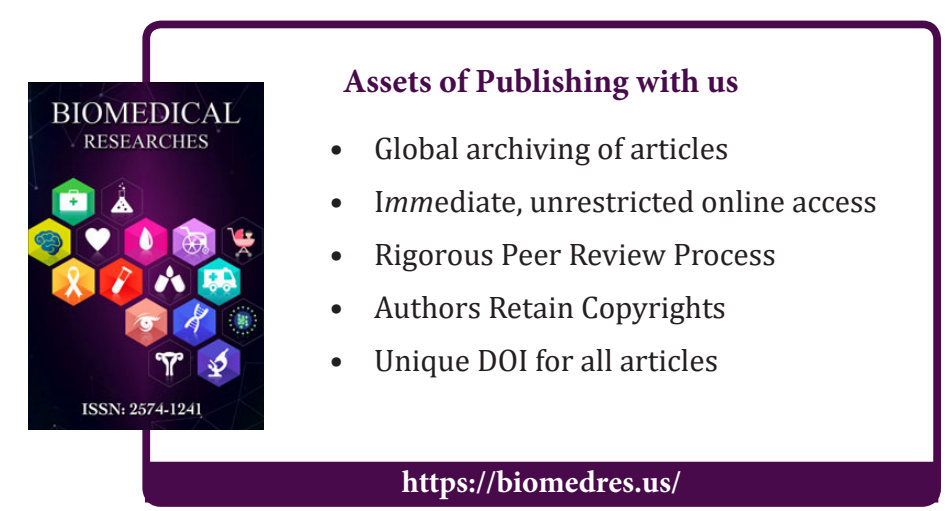

